\title{
Cost and quality of life in patients with severe chronic hand eczema refractory to standard therapy with topical potent corticosteroids
} Paolo A. Cortesi ${ }^{1,2}$, Luciana Scalone ${ }^{1,2}$, Andrea Belisari ${ }^{2}$, Domenico Bonamonte ${ }^{3}$, Serafinella Patrizia Cannavò ${ }^{4}$, Antonio Cristaudo ${ }^{5}$, Ornella De Pità ${ }^{6}$, Rosella Gallo ${ }^{7}$, Alberto Giannetti ${ }^{8}$, Massimo Gola9 Paolo D. Pigatto ${ }^{10}$ and Lorenzo G. Mantovani ${ }^{2,11}$

${ }^{1}$ Research Centre on Public Health (CESP), University of Milan-Bicocca, 20052 Monza, Italy, ${ }^{2}$ CHARTA Foundation, 20122 Milano, Italy, ${ }^{3}$ Unit of Dermatology, Department of Biomedical Science and Human Oncology, University of Bari 'Aldo Moro', 70124 Bari, Italy, ${ }^{4}$ Unit of Dermatology, Department of Clinical and Experimental Medicine, University of Messina, 98168 Messina, Italy, ${ }^{5}$ Laboratory of Clinical Pathology, Department of Allergology and Laboratory of Skin Physiopathology, Institute San Gallicano, IRCCS, IFO, 00144 Roma, Italy, ${ }^{6}$ Laboratory of Immunology, Istituto Dermopatico dell'Immacolata (IDI)-IRCCS, 00167 Roma, Italy, ${ }^{7}$ Section of Dermatology, DISSAL - Department of Health Sciences, University of Genoa, 16132 Genoa, Italy, ${ }^{8}$ Division of Dermatology, University of Modena and Reggio Emilia, 41100 Modena, Italy, ${ }^{9}$ Allergological and Occupational Dermatology Unit, Department of Critical Care Medicine and Surgery, University of Florence, 50129 Firenze, Italy, ${ }^{10}$ Department of Biomedical Science for Health IRCCS, Galeazzi Hospital, University of Milan, 20161 Milano, Italy, and ${ }^{11}$ Department of Clinical Medicine and Surgery, University Federico II of Naples, 80131 Naples, Italy

doi:10.1111/cod. 12130

\section{Summary}

Background. Little is known about the socio-economic burden of severe chronic hand eczema in patients refractory to treatment with potent corticosteroids.

Objectives. To estimate the socio-economic burden of severe chronic hand eczema refractory to potent topical corticosteroids, and to establish an algorithm for the estimation of the health-related quality of life EuroQol five-dimensional (EQ-5D) utility index from the Dermatology Life Quality Index (DLQI) summary score.

Methods. A multicentre cost of illness study was conducted, adopting the societal perspective. Adult patients with severe and refractory chronic hand eczema were enrolled. Direct (e.g. drug treatment and travel) and indirect (i.e. loss of productivity) mean costs/patient-month were estimated. Health-related quality of life was assessed with the EQ-5D and DLQI questionnaires. An ordinary least square regression model was used to investigate relationships between health-related quality of life scores.

Results. One hundred and four valid patients (mean age 44.5 years, 39.4\% male) participated. Overall mean costs were $€ 418.3 /$ patient-month: loss of productivity contributed $43.7 \%$, followed by hospitalization $(16.1 \%)$ and travel $(10.3 \%)$. Healthrelated quality of life scores were, on average, 0.50 (EQ-5D utility) and 11.3 (DLQI). Utility and DLQI summary were significantly related to each other.

Conclusions. Wellbeing and loss of productivity are the most important consequences in these patients. Appropriate treatment is necessary to improve patient health and productivity, which will contribute to reducing societal costs.

Key words: chronic hand eczema; cost of illness; health-related quality of life; healthcare costs; loss of productivity; refractoriness to therapy

Correspondence: Luciana Scalone, Department of Statistics and Quantitative Methods, CESP - Research Centre On Public Health, University of Milano-Bicocca, Villa Serena, Via Pergolesi 33, I-20052 Monza, Italy. Tel: +39 3476749912; Fax: +39 02 700536422. E-mail: luciana.scalone@fondazionecharta.org

Disclosures: P.A.C., L.S., A.B., D.B., S.P.C., A.C., O.D.P., A.G., M.G., P.D.P. and L.G.M. have no conflict of interest to declare. R.G. has given lectures at meetings sponsored by Basilea, has been consultant to the company, and has received honoraria from Basilea.

Funding: This study was financially supported with an unrestricted grant received from Basilea Pharmaceutica Ltd. 
Some studies conducted in northern Europe have shown that the incidence of chronic hand eczema is 0.7 cases per 1000 people per year in high-risk occupational groups ( 1 , 2 ). The proportion of patients with severe chronic hand eczema has been estimated to be $5-7 \%$ of all patients with hand eczema, and those considered to be refractory to potent topical corticosteroids were estimated to represent $2-4 \%$ (3). In a more recent registry project of the German Dermatological Society, conducted in 66 German dermatology centres, $21.9 \%$ of all chronic hand eczema cases were graded as severe and $49.5 \%$ as moderate (4).

In general, chronic hand eczema patients can be managed with emollients, topical corticosteroids, and avoidance of irritants/allergens, but some severe cases are refractory to this therapy (3). However, treating chronic hand eczema is often difficult. Systemic treatments may provide temporary remission, but are not always suitable for long-term disease control (3). Recently, alitretinoin (9-cis-retinoic acid) has been approved for the treatment of severe refractory chronic hand eczema $(5,6)$; it showed efficacy in the treatment of severe chronic hand eczema that was unresponsive to potent topical corticosteroids $(5-7)$.

Severe chronic hand eczema may lead to severe impairment of health-related quality of life, prolonged absence from work, or even loss of job and early retirement $(8-11)$. In some countries, chronic hand eczema has been identified as the most expensive occupational disease $(8,12)$.

In addition to the clinical and epidemiological implications, medical costs, loss of productivity and impairment of patients' wellbeing can significantly contribute to the high burden of chronic hand eczema. Knowledge of the socio-economic burden of chronic hand eczema is necessary to understand how treatments can be provided to maximize their benefits at acceptable cost. However, little is known about the burden of chronic hand eczema; few studies have been performed so far in some northern European countries $(8,10,12,13)$. The studies available have generally focused on specific categories of patients with jobs posing a high risk or associated with a diagnosis of hand eczema, and on only some aspects of the burden (e.g. loss of productivity) $(8,12)$. Furthermore, although it has been recognized that healthrelated quality of life can be significantly compromised in severe chronic hand eczema patients, the few data available so far have been obtained only with conditionspecific instruments, such as the Dermatology Life Quality Index (DLQI) (e.g. 10, 14), and none of the existing data are on severe chronic hand eczema patients obtained with a generic health-related quality of life instrument suitable for calculating utilities and quality-adjusted life years (QALYs), which are useful for estimation of the costeffectiveness of the different treatment options for severe and refractory chronic hand eczema $(13,15)$.

The main objective of the present study was to estimate the socio-economic burden of severe chronic hand eczema refractory to standard therapy with potent topical corticosteroids. Furthermore, we aimed to calculate an algorithm suitable for converting the DLQI summary score into the EuroQol five-dimensional (EQ-5D) utility index, which is the most frequently used index for the estimation of QALYs in cost-utility analyses.

\section{Materials and Methods}

\section{Study design}

A naturalistic, multicentre, longitudinal, retrospective, prevalence-based cost of illness (COI) study was carried out. Results from COI studies can be a useful aid to policy decision-making, to underline the importance of a disease with respect to its socio-economic impact, together with the impact on morbidity and mortality. Furthermore, COI studies may allow identification of the drivers of costs of the disease, and may help in the design of more appropriate pharmacoeconomic evaluations for estimation of the costeffectiveness of treatment options (16).

In this study, we estimated medical and non-medical costs (direct costs), loss of productivity (indirect costs) and health-related quality of life (intangible costs) attributable to the presence and treatment of severe chronic hand eczema refractory to standard therapy. The study was conducted with a retrospective time horizon of up to 8 weeks before enrolment. Analyses on costs were conducted from the societal perspective, that is, including the perspectives of the third-party payer (National Health Service), of patients, and of family care-givers.

\section{Subjects and setting}

This study was part of a larger project aimed at assessing the prevalence of chronic hand eczema among patients accessing tertiary referral dermatology centres and diagnosed with hand eczema (17). In particular, the COI study was targeted at adult (age $\geq 18$ years) patients with severe chronic hand eczema refractory to standard therapy with potent topical corticosteroids. Six dermatology centres throughout Italy participated in the COI study, out of the 14 centres that took part in the epidemiological study. In each centre, the first 40 valid patients or all those accessing that centre in 1 year could be enrolled in the COI study.

To identify the eligible patients, the following criteria, similar to those adopted by Ruzicka et al., were used (5). To 
be defined as chronic, patients had to have had symptoms of hand eczema for $\geq 6$ months (in the absence of external causative factors); among chronic patients, those with current relapse were identified as chronic relapsed. For definition of a patient as severe, physicians evaluated the general clinical status of the patient, and the functional impact of the disease on the patient's professional and everyday activity, using as a guide for clinical evaluation the Physician's Global Assessment (PGA) score combined with the modified Total Lesion Symptom Score (mTLSS) and with the photographic guide (18).

The PGA and mTLSS were developed as a verbal description corresponding to chronic hand eczema severity grades depicted in a published and validated photographic guide (18). The PGA is a five-level score: clear, almost clear, mild disease, moderate disease, and severe disease. Each level is associated with a description of hand eczema intensity and a percentage of hand surface involved. The mTLSS consists of seven items: (1) erythema, (2) scaling, (3) lichenification/hyperkeratosis, (4) vesiculation, (5) oedema, (6) fissures, and (7) pruritus/pain. Each item ranges from 0 (none) to 3 (severe). These items are summarized in a score ranging from 0 to 21, with a higher score indicating a more severe condition. The photographic guide classifies severity of hand eczema in five levels: clear, almost clear, moderate, severe, and very severe. Each level is represented by four photographs showing both dorsal and palmar views of the hands (18).

Finally, patients were defined as refractory to standard therapy with potent topical corticosteroids when (i) they had avoided irritants and allergens, if identified, without significant improvement, (ii) other disorders that may mimic chronic hand eczema had been excluded, (iii) they had received standard skin care, including emollients and barrier protection as appropriate, without significant improvement, and (iv) they had also received treatment with topical corticosteroids for at least 8 weeks in total, within 6 months before enrolment, with either no response or only a transient response. The previous 8 weeks of treatment had to include 4 weeks of therapy with the most potent class of topical corticosteroid, for example clobetasol propionate.

The study was performed in accordance with the guidelines of the International Conference on Harmonization for Good Clinical Practice as stipulated in the Declaration of Helsinki (19). Local Ethics Committee approval was obtained at each of the participating study sites. To participate, each patient had to sign an informed consent form.

\section{Data}

The following data were collected: socio-demographic (age, sex, education, and marital and employment status) and clinical characteristics (e.g. duration from the diagnosis of hand eczema, and the presence of concomitant conditions), data on direct medical costs (e.g. drug treatment and hospitalizations) and on direct nonmedical costs (e.g. costs of travel to reach the dermatology centre for visits or examinations), which refer to items that are more closely related with the disease and its treatment, indirect costs, which refer to changes in productivity resulting from the disease and its management, and intangible costs, that is, effects on patients' health-related quality of life.

With regard to employment status, which is expected to be potentially related to the patients' hand eczema, we identified, for each participant, the working activity performed at the time of enrolment. Patients who were classified as having employment were further subgrouped into working categories according to their occupation. The classification of Senghal et al. was used to help perform this classification (20).

Direct and indirect costs. Direct medical costs were assessed with the information obtained by the clinical investigator on consumption of the following medical resources: pharmacological and non-pharmacological treatment (e.g. emollients, galenic formulations, and ultraviolet irradiation), other products or instruments, such as gloves or gauze bandages, vacuum cleaners, and cosmetics, hospital admissions (inpatient and/or dayhospital) for reasons attributable to hand eczema, medical specialist consultations, and laboratory and instrumental tests. Direct non-medical costs were assessed with the information obtained from the patient on the amount of travel resulting from eczema and the related amount of money spent. Direct costs were quantified in monetary terms by multiplying the amount of each resource consumed by the corresponding unit cost, according to prices or tariffs applying in Italy in 2011. The perspectives of both the patient and the NHS were adopted to estimate these costs, according to the actual payer. For costs paid by the NHS, unit costs of pharmacological treatment were obtained from the Italian Drug Agency price list (21). Costs of hospital admissions were calculated according to the Diagnosis Related Group regional tariffs (22). Costs for diagnostic tests and medical consultations were obtained from the regional outpatient lists (23). In cases where patient out-of-pocket costs occurred, the information on cost reported by the patients was used.

For the estimation of indirect costs, that is, costs resulting from productivity losses, a short version of 
the Health and Labour Questionnaire (SF-HLQ) was administered to the patients (24). This consists of three modules: absenteeism from paid work, production losses without absenteeism from paid work, and hindrance in the performance of paid and unpaid work. Patients' absenteeism from paid work was quantified in monetary terms, with the human capital approach (16). To assign unit costs to the days lost from work, we used the average gross salaries reported by the Italian Institute of Statistics for each work category (25). For patients who were not in paid work, the number of days lost from work and the related monetary value were assumed to be zero, as this information is not asked for in the SF-HLQ questionnaire.

Health-related quality of life. Health-related quality of life was assessed with a battery of two well-established and standardized instruments that are suitable for patients with dermatological problems. Specifically, the generic EQ-5D (26) and the condition-specific DLQI were used $(11,27,28)$. The main difference between the two instruments, which justifies the use of both of them, is that the EQ-5D allows comparisons among different populations (e.g. with healthy people or people with other conditions) and the estimation of utilities for economic evaluations (29), whereas the specific DLQI is expected to give more precise information on the influence of the hand eczema experience (symptoms, flares, and treatment) on patients' health-related quality of life (11). The DLQI and the EQ-5D have been widely used in several different dermatological conditions $(10,11,28,30-32)$.

With the EQ-5D, the respondents are asked about their health-related quality of life on the current day. It consists of two main parts. The first part generates a health profile (EQ-5D profile) composed of five domains, namely 'mobility', 'self-care', 'anxiety or depression', 'usual activities', and 'pain or discomfort', each one with three levels of severity ('no problem', 'some/moderate problems', and 'extreme problems/impossible to do'). The second part of the questionnaire consists of a visual analogue scale (VAS) that measures overall healthrelated quality of life, ranging from 0 (worst imaginable health state) to 100 (best imaginable health state) (26). The results from the EQ-5D descriptive system can be converted to a utility index, which is useful for conducting economic evaluations, by means of an algorithm that uses population-based (social) values (33-35). Because specific conversion values for the Italian population are not yet available, to convert our EQ-5D descriptive system results into an EQ-5D utility index, we used social values from the United Kingdom (34).

The DLQI consists of 10 items: (1) itching and scratching, (2) embarrassment, (3) housework, (4) dressing, (5) social relationships/spare time, (6) sport, (7) work/study, (8) partner/relatives, (9) sex, and (10) treatment. Each question relates to the last week, and ranges from 0 (no impairment) to 3 (maximum impairment). These items are summarized in a score ranging from 0 to 30 , indicating: $0-1$, no effect at all on the patient's life; $2-5$, a small effect on the patient's life; $6-10$, a moderate effect on the patient's life; $11-20$, a very large effect on the patient's life; and 21-30, an extremely large effect on the patient's life (36). The Italian version of the index has been shown to be feasible and reliable, and to have good levels of content validity (27).

\section{Statistical analyses}

The socio-demographic, clinical and health-related quality of life characteristics of our sample were described with the use of proportions for categorical data, mean and/or median as central tendency parameters for continuous data, and standard deviation, minimum values and maximum values as dispersion parameters.

The consumption of healthcare resources is expressed as the proportion of patients consuming each healthcare item, and as mean (minimum-maximum) number of visits, days, and sessions per patient-month. Monetary values are reported as mean $€ /$ patient-month. Indirect costs are reported in terms of proportions of patients losing at least 1 day of productivity, and as mean (minimum-maximum) days/patient-month of productivity lost. Absenteeism from paid work was quantified in monetary terms, and is reported as mean $€ /$ patientmonth.

Because of the highly skewed distribution of cost variables, we report as a variability measure the distribution of both costs and days of productivity lost per patient per month.

A univariate regression model was used to estimate the association between the EQ-5D utility index and the DLQI summary score. Furthermore, a multivariable regression model was used to estimate this association, with adjustment for age, sex, and diseases severity. Actually, more models were explored with a stepwise procedure, in order to investigate and select the most efficient one according to logical consistency and statistical significance of the regression coefficients, and according to the goodness of fit model and the parsimony criterion. Only the most efficient model is specified in the article. In the model, the dependent variable was the EQ-5D utility included as a continuous variable. The independent variables were DLQI summary score, age, sex, PGA score, and mTLSS summary score. DLQI summary score, age and mTLSS summary score were included in the model 
as continuous variables, and PGA score was stratified in three levels ('almost clear or mild disease', 'moderate disease', and 'severe disease'), and was included with two dummy variables (three levels minus the 'almost clear or mild disease' reference one). Sex was included as dummy variable, coded as 0 for male and 1 for female. Confidence intervals (CIs) of 95\%, standard errors and $p$ values of $<0.05$ (two-tailed tests) were used to define the statistical significance of the results. Bootstrap resampling was used to calculate standard errors and CIs. All analyses were performed with SPSS ${ }^{\mathrm{TM}}$ version 18.0 software (SPSS, Chicago, IL, USA).

\section{Results}

\section{Sample description}

A total of 110 patients were enrolled during 2009 and 2010. Six were excluded from the analyses, because 4 were actually not severe, and 2 were not refractory to standard therapy. Hence, the valid study sample included 104 patients. Table 1 shows the patients' sociodemographic and clinical characteristics.

\section{Resource consumption and loss of productivity}

During the 8 weeks before the visit, 103 (99.0\%) patients took at least one drug for their chronic hand eczema treatment. Figure 1 shows that almost $60 \%$ of them used at least one potent topical corticosteroid, $51 \%$ used very potent topical corticosteroids, $\sim 20 \%$ used systemic antihistamines, $17 \%$ used systemic corticosteroids, and $14 \%$ used potent topical corticosteroids plus antibiotics. Seventeen per cent of the patients used at least one antibiotic and/or a combination of corticosteroids and antibiotics. Forty-three per cent of the patients took only one of the drug classes specified in Fig. 1, 31\% took two drug classes, and $24 \%$ took three to six different drug classes.

Overall, $>90 \%$ of the patients used nonpharmacological treatment and/or had medical consultations (Table 2). Diagnostic tests were performed in two thirds of the patients, and $\sim 10 \%$ of patients were hospitalized because of severe chronic hand eczema.

With regard to non-medical resources, patients travelled, on average, two times per month for reasons attributable to their condition. In particular, $51.9 \%$ of patients travelled between one and two times, 29.5\% travelled between two and five times, and $4.9 \%$ travelled five times or more.

With regard to loss of productivity, we found that $75.2 \%$ of the patients, regardless of their working status at enrolment, received help from an informal care-giver (e.g. father, mother, brother or sister, son, friend, spouse, or cohabitant) to manage their condition. Approximately $49.0 \%$ of patients were hindered in performing usual activities or did not perform them at all because of health problems (Table 3). Furthermore, among the $61.5 \%$ of patients who had a paid job during the 8 weeks before enrolment, $45.3 \%$ lost at least one working day, and 1 patient declared a loss of job during that period. On average, patients with paid work lost 4.9 working days/patient-month. In this group of patients having at least one working day lost, patients were off work for $\sim 50 \%$ of the 8 weeks before the visit. Also, $6.3 \%$ reported that they were unable to work for a period longer than 8 weeks. Furthermore, $\sim 65 \%$ of patients with paid work reported health problems that interfered with their efficiency at work, with an average of 10.1 days/patient-month of work being performed while they were suffering from health problems.

\section{Costs}

Overall costs corresponded to an average of $€ 418.3 /$ patient-month, with a minimum of $€ 34.3 /$ patient-month and a maximum of $€ 2304.4 /$ patient-month (Table 4): medical costs contributed $46 \%$ of total costs, mainly attributable to hospitalizations, followed by indirect costs $(44 \%)$, corresponding to $€ 182.9 /$ patient-month. When indirect costs were calculated by considering only patients with paid work, the mean total indirect cost was $€ 297.3 /$ patient-month. Finally, direct non-medical costs contributed $10 \%$ of total costs.

Costs had a skewed distribution: almost half $(41.4 \%)$ of the patients actually cost no more than $€ 150 /$ patientmonth, $25.0 \%$ cost between $€ 150 /$ patient-month and $€ 300 /$ patient-month, $18.3 \%$ cost between $€ 300 /$ patient-month and $€ 1000 /$ patient-month, and $15.4 \%$ of the patients generated the highest costs, ranging between $€ 1000 /$ patient-month and $€ 2304$.4/patient-month.

\section{Health-related quality of life}

The mean EQ-5D VAS score was 60.4 (minimum $=0.0$, maximum $=100.0$ ), with 1 patient reporting a score of 0 , and 2 reporting a score of 100 . Ninety-six per cent of the patients reported some or severe pain or discomfort, $73 \%$ had problems in performing usual activities, 55.8\% reported anxiety/depression, and $52.9 \%$ had problems with self-care (Fig. 2), corresponding to a mean utility 
Table 1. Patients' socio-demographic and clinical characteristics $(\mathrm{n}=104)$

\begin{tabular}{|c|c|c|}
\hline \multicolumn{2}{|l|}{ Variable description } & \multirow{2}{*}{$\begin{array}{c}\text { Values } \\
42.8(18.0-80.4) \\
44.5(15.0)\end{array}$} \\
\hline Age in years & $\begin{array}{l}\text { Median (minimum-maximum) } \\
\text { Mean (SD) }\end{array}$ & \\
\hline Sex, $n(\%)$ & $\begin{array}{l}\text { Male } \\
\text { Female }\end{array}$ & $\begin{array}{l}41(39.4) \\
63(60.6)\end{array}$ \\
\hline Education ${ }^{\mathrm{a}}$, n (\%) & $\begin{array}{l}\text { Primary school } \\
\text { Lower secondary school } \\
\text { Upper secondary school } \\
\text { Graduate } \\
\text { Postgraduate }\end{array}$ & $\begin{array}{l}15(14.6) \\
39(37.8) \\
36(35.0) \\
13(12.6) \\
0\end{array}$ \\
\hline Working status, n (\%) & $\begin{array}{l}\text { Patients with paid work } \\
\text { Housewife } \\
\text { Retired } \\
\text { Unemployed } \\
\text { Student }\end{array}$ & $\begin{array}{l}63(60.6) \\
18(17.3) \\
10(9.6) \\
7(6.7) \\
6(5.8)\end{array}$ \\
\hline $\begin{array}{l}\text { Type of job (among } 63 \text { patients } \\
\text { with paid work), } \mathrm{n}(\%)\end{array}$ & $\begin{array}{l}\text { Craft and related trades workers } \\
\text { (builders, plumbers, electricians) } \\
\text { Handicraft workers } \\
\text { Food processing and related workers } \\
\text { Health professionals } \\
\text { Teaching professionals } \\
\text { Cleaners } \\
\text { Computing professionals } \\
\text { Computer-associated professionals } \\
\text { Agricultural workers } \\
\text { Mechanical machinery assemblers } \\
\text { Launderers } \\
\text { Motor vehicle drivers } \\
\text { Cashiers and related clerks } \\
\text { Stall and market salespersons } \\
\text { Other }\end{array}$ & $\begin{array}{l}8(12.7) \\
8(12.7) \\
7(11.1) \\
6(9.5) \\
4(6.3) \\
3(4.8) \\
3(4.8) \\
3(4.8) \\
2(3.1) \\
2(3.1) \\
2(3.1) \\
2(3.1) \\
2(3.1) \\
2(3.1) \\
9(14.3)\end{array}$ \\
\hline Chronicity of hand eczema, n (\%) & $\begin{array}{l}\text { Chronic } \\
\text { Chronic and relapsed }\end{array}$ & $\begin{array}{l}33(31.7) \\
71(68.3)\end{array}$ \\
\hline Years from appearance of symptoms & $\begin{array}{l}\text { Median (minimum-maximum) } \\
\text { Mean (SD) }\end{array}$ & $\begin{array}{c}4.0(0.5-30) \\
6.7(6.6)\end{array}$ \\
\hline Years from diagnosis & $\begin{array}{l}\text { Median (minimum-maximum) } \\
\text { Mean (SD) }\end{array}$ & $\begin{array}{c}3.0(0-30.0) \\
5.4(6.2)\end{array}$ \\
\hline Patients at first visit in a dermatologyc & ma, n (\%) & $20(19.2)$ \\
\hline PGA score, n (\%) & $\begin{array}{l}\text { Clear } \\
\text { Almost clear } \\
\text { Mild disease } \\
\text { Moderate disease } \\
\text { Severe disease }\end{array}$ & $\begin{array}{c}0 \\
1(0.9) \\
14(13.5) \\
47(45.2) \\
42(40.4)\end{array}$ \\
\hline mTLSS sum score & $\begin{array}{l}\text { Median (minimum-maximum) } \\
\text { Mean (SD) }\end{array}$ & $\begin{array}{c}14.0(4.0-21.0) \\
14.3(4.2)\end{array}$ \\
\hline Concomitant atopic diseases, n (\%) & $\begin{array}{l}\text { Allergic rhinitis } \\
\text { Atopic dermatitis } \\
\text { Asthma }\end{array}$ & $\begin{array}{c}25(24.0) \\
16(15.4) \\
10(9.6)\end{array}$ \\
\hline
\end{tabular}

mTLSS, modified Total Lesion Symptom Score; PGA, Physician's Global Assessment; SD, standard deviation.

a Percentages were estimated with the exclusion of 1 patient who gave no information on education. 


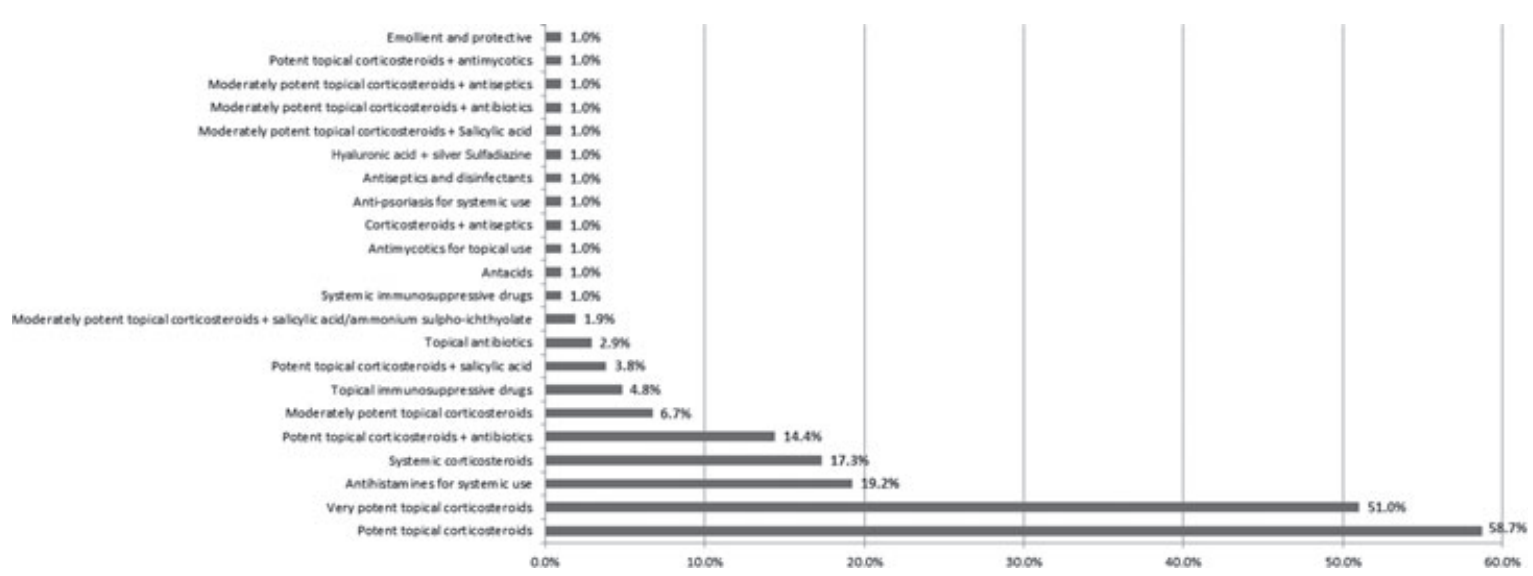

Fig. 1. Chronic hand eczema drug treatment during the 8 weeks before the visit. Percentages refer to the patients taking the drug at least once during the 8 weeks before the visit, either alone or with other drugs. The percentages reported do not necessarily sum up to $100 \%$.

Table 2. Medical and non-medical resources (excluding drugs) consumed for reasons attributable to hand eczema

Type of resource

Non-pharmacological treatment ${ }^{\mathrm{a}}$

$\mathrm{n}(\%)$ patients using any type of treatment

$92(90.2)$

Mean (minimum-maximum) treatments/patient-month

$1.38(0.0-7.0)$

Of which:

$\mathrm{n}(\%)$ patients using emollients

89 (87.3)

Mean (minimum-maximum) emollients/patient-month

$1.2(0.5-5.4)$

$\mathrm{n}(\%)$ patients using galenic products

Mean (minimum-maximum) galenic products/patient-month

$16(15.7)$

$n(\%)$ patients using other therapies (e.g. detergents/soaps, antiseptics)

$1.1(0.5-2.1)$

Mean (minimum-maximum) other therapies/patient-month

$10(9.8)$

n (\%) patients using UV therapy

$0.8(0.5-2.1)$

$1(0.9)$

Mean (minimum-maximum) UV treatments/patient-month

$4.0(4.0-4.0)$

Other products ${ }^{\mathrm{a}}$ (gloves or gauze bandage, cosmetics, vacuum cleaner, etc)

$\mathrm{n}(\%)$ patients using other products

Mean (minimum-maximum) other products/patient-month

Diagnostic tests (patch test, prick test, RAST, PRIST, atopy patch test, skin biopsy, test for hives, and immunofluorescence)

$\mathrm{n}(\%)$ patients undergoing diagnostic tests

$67(64.4)$

Mean (minimum-maximum) tests/patient-month

$0.6(0.0-2.1)$

Medical specialist consultations (dermatologist, allergist, occupational physician, immunologist, police doctor)

$\mathrm{n}(\%)$ patients undergoing medical consultation

$96(92.3)$

Mean (minimum-maximum) visits/patient-month

Hospitalizations

$\mathrm{n}(\%)$ patients with any hospital admission

$10(9.6)$

Of which:

$\mathrm{n}(\%)$ patients with ordinary hospitalization

$7(6.7)$

Mean (minimum-maximum) days of ordinary hospitalization per patient-month

$0.2(0.0-5.4)$

$\mathrm{n}(\%)$ patients with day hospital access

Mean (minimum-maximum) day hospital attendances per patient-month

Severe chronic hand eczema-related travel

Mean (minimum-maximum) number of journeys per patient-month

PRIST, paper radioimmunosorbent test; RAST, radioallergosorbent test; UV, ultraviolet.

${ }^{a}$ Percentages were estimated with the exclusion of patients with data missing: up to 2 patients did not provide one or more data items. 
Table 3. Problems in performing usual activities during the 8 weeks before enrolment $(n=104)$

\begin{tabular}{llc}
\hline Variable description & & Number of patients (\%) \\
\hline $\begin{array}{l}\text { Household work (e.g. preparing food, cleaning the } \\
\text { house, doing the washing) }\end{array}$ & Done, although hindered by health problems & $67(64.4)$ \\
$\begin{array}{l}\text { Going shopping (e.g. daily groceries, shopping, visit to } \\
\text { bank or post office) }\end{array}$ & Not done, because of health problems & $13(12.5)$ \\
$\begin{array}{l}\text { Daily work and various tasks (e.g. maintenance work on } \\
\text { house, garden, bicycles, and vehicles) }\end{array}$ & Not done, because of health problems & $63(60.6)$ \\
$\begin{array}{l}\text { Specific activities for or with the children sharing your } \\
\text { household } \text { (e.g. personal care, play, taking the } \\
\text { children to school, helping with their homework) }\end{array}$ & Done, although hindered by health problems & $55(52.9)$ \\
\hline
\end{tabular}

a Percentages were estimated with the exclusion of 11 patients with data missing and 13 patients without children sharing their household.

Table 4. Overall costs

\begin{tabular}{lcc}
\hline & \multicolumn{2}{c}{ Value } \\
\cline { 2 - 3 } Variable description & $\begin{array}{c}\text { Mean } € / \text { patient-month } \\
\text { (minimum-maximum) }\end{array}$ & $\%$ \\
\hline Indirect costs & $182.9(0-1616.2)$ & 43.7 \\
Hospitalizations & $67.3(0-913.9)$ & 16.1 \\
Travel & $43.4(2.68-803.6)$ & 10.3 \\
Medical consultation & $41.0(0-401.8)$ & 9.8 \\
Other products & $27.2(0-935.9)$ & 6.5 \\
Diagnostic examinations & $19.6(0-153.8)$ & 4.7 \\
Non-pharmacological therapy & $18.7(0-103.7)$ & 4.5 \\
Pharmacological therapy & $18.2(0-92.9)$ & 4.4 \\
Total costs & $418.3(34.3-2304.4)$ & 100 \\
\hline
\end{tabular}

index of 0.50 (minimum $=0.24$, maximum $=1.00$ ). The mean DLQI summary score was 11.3 (minimum $=1$, maximum $=30$ ), with $82.7 \%$ of patients reporting a moderate to extremely large effect of hand eczema on their life (Fig. 3).

The results of the univariate regression model showed a significant linear relationship between the EQ-5D utility index and the DLQI summary score. The significant association was confirmed with the more efficient multivariable model, in which the mTLSS summary is also included (Table 5). With these results, it is possible to calculate the utility index from the DLQI summary score, with either model, depending on the availability of the mTLSS score. For instance, if the mTLSS score is not available and the DLQI score is 12 , the utility index is estimated to be 0.484 . Instead, if a mTLSS score is also available (e.g. 21), the utility score is estimated to be 0.350

(1) Utility index $=0.784-(0.025 \times$ DLQI summary score)

(2) Utility index $=1.010-(0.020 \times$ DLQI summary score $)-(0.020 \times$ mTLSS summary score $)$

\section{Discussion}

To the best of our knowledge, this is the first study to evaluate the socio-economic impact of severe chronic hand eczema refractory to standard therapy in a Mediterranean country. The centres involved in the project are located thoughout Italy, to account for the geographical and climatic differences.

Overall, the results of our study are in line with others showing that severe chronic hand eczema has a high burden and may lead to severe impairment of health-related quality of life, prolonged sick leave, and loss of employment $(8-11)$.

The overall cost estimated for patients with severe chronic hand eczema refractory to standard therapy was $€ 418.3 /$ patient-month, and slightly higher (€470.9/patient-month) when we focused on the patients classified as severe with only the PGA score. Our estimates were also higher than those recently obtained in Germany in patients who were severe, chronic, and refractory to topical steroids (classes II-IV) (€267.1/patient-month) (10). On the one hand, costs between different healthcare systems can differ because unit costs are different per

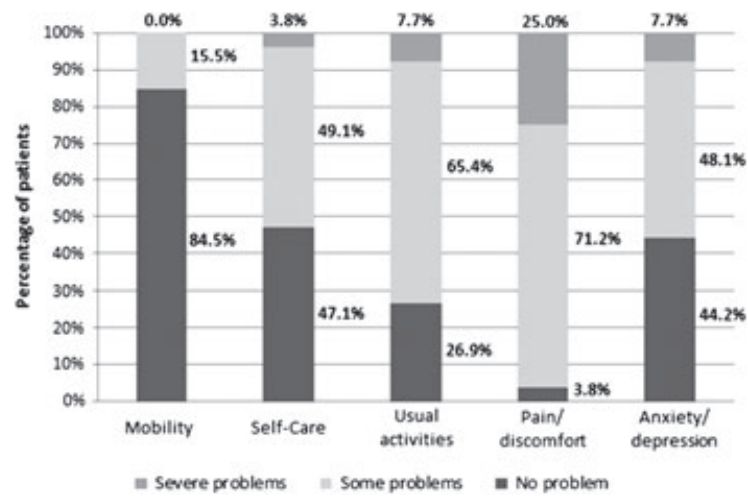

Fig. 2. EQ-5D profile. 


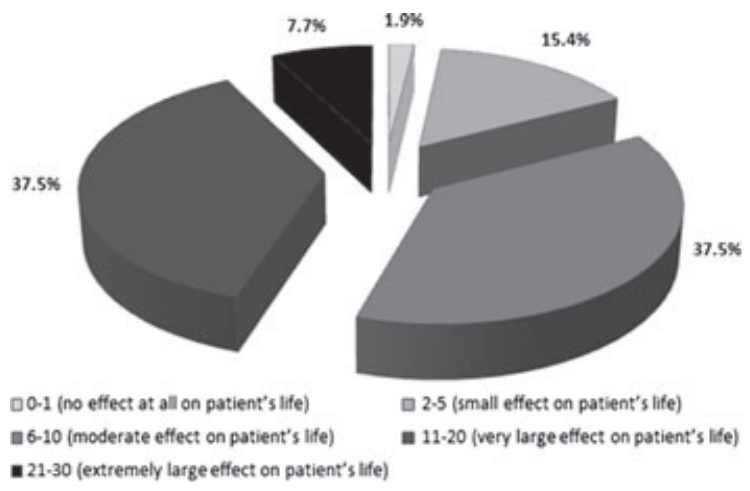

Fig. 3. Distribution of patients according to the Dermatology Life Quality Index summary score levels estimated.

second. However, we also found a difference in working days lost per patient-month (4.9 days/patient-month versus 0.6 days/patient-month), and hence in related indirect costs (€182.9/patient-month versus €32.2/patientmonth), in Italy and Germany, respectively. An average of 4.7 working days lost per patient-month was found among the patients classified as severe with PGA only, slightly lower than what was found in the entire sample. Approximately $75 \%$ of patients received help from an informal care-giver to manage their condition, and $\sim 50 \%$ were hindered in performing usual activities or did not perform them at all because of health problems.

The patients enrolled in the present study showed more impairment of health-related quality of life than those in other studies. The mean DLQI summary score was 11.3, higher than the 6.7 and 7.8 reported in the studies by Augustin et al. (10) and Cvetkovski et al. (37), respectively. Patients who were severe, based on the PGA score only, in the study by Augustin et al. had a mean DLQI score of 14.3, which was similar to our results (14.5) (10).
Also, this study is the first to use a generic healthrelated quality of life instrument focusing on patients with severe and refractory chronic hand eczema; previous studies used these generic instruments for hand eczema patients, without distinguishing the different stages of the disease $(28,30,32,38)$. We found that health-related quality of life of target patients was similar to or slightly worse than that of patients with moderate to severe plaque psoriasis and refractory to therapy (not including inhibitors of human tumour necrosis factor- $\alpha$ ): we found a mean VAS score of 60.4 , which is similar to the mean score (60.8) estimated in the study by Deudén et al. (31), and the mean EQ-5D utility was 0.50, which is lower than in that study (0.66).

A significant relationship between EQ-5D utility and DLQI summary score was found. In particular, we estimated coefficients that can be used to transform DLQI data available from the different projects $(5,10)$ into a utility index, if this is not directly detected with a suitable instrument. These algorithms could be useful for performing more complete health economic evaluations on severe refractory chronic hand eczema patients, as required in some healthcare systems $(13,15)$. This study has some potential limitations: some criticisms could be made with regard to the approach used to estimate indirect costs. Indirect costs were monetized only for patients with paid work, and this led to an underestimation of such costs, owing to the lack of data on loss of productivity for the unemployed, housewives, students, or retired. However, we provide a picture of the study sample according to the percentage of patients reporting problems in usual activities, to give a more accurate and informative description of the indirect costs. Another limitation could be the applicability of the results in other countries: possible differences in the results can be expected if different items or unit costs are applicable (for example, if hospital costs are not reimbursed with the

Table 5. Relationship of health-related quality of life EQ-5D utility index with the Dermatology Life Quality Index (DLQI) summary score

\begin{tabular}{|c|c|c|c|c|}
\hline \multirow[b]{2}{*}{ Regression analyses } & \multirow[b]{2}{*}{ Regression coefficent (SE) } & \multirow[b]{2}{*}{$p$-value } & \multicolumn{2}{|c|}{$95 \% \mathrm{Cl}$} \\
\hline & & & Lower bound & Upper bound \\
\hline \multicolumn{5}{|l|}{ Univariate model $^{\mathrm{a}}$} \\
\hline Constant & $0.784(0.055)$ & $<0.001$ & 0.709 & 0.875 \\
\hline DLQI summary score & $-0.025(0.004)$ & $<0.001$ & -0.030 & -0.020 \\
\hline \multicolumn{5}{|l|}{ Multivariate model ${ }^{\mathrm{a}}$} \\
\hline Constant & $1.010(0.093)$ & $<0.001$ & 0.844 & 1.138 \\
\hline DLQI summary score & $-0.020(0.004)$ & $<0.001$ & -0.028 & -0.011 \\
\hline mTLSS summary score & $-0.020(0.007)$ & 0.004 & -0.031 & -0.008 \\
\hline
\end{tabular}

CI, confidence interval; mTLSS, modified Total Lesion Symptom Score; SE, standard error.

a The univariate model includes only one independent variable, whereas the multivariable model includes more independent variables, to adjust for potential confounders. 
DRG system or if different medical consultation visits or examinations are adopted and their unit cost is different from that in the Italian healthcare system). To expand the applicability of our results, we reported the consumption of each single item, in order to give the opportunity to use them in other contexts, applying different unit costs.

A further criticism could be made concerning the approach used to classify the patients as severe. In previous studies, only the PGA score was used to identify severe patients, whereas, in our study, clinicians considered it to be more appropriate to use a combination of parameters: the functional impact of the disease on the patient's professional and everyday activity, and the general clinical status of the patient, using the PGA score combined with the mTLSS and the photographic guide.

In conclusion, this study provides, for the first time in a Mediterranean country, a complete picture of the high societal burden attributable to chronic hand eczema refractory to standard therapy. Loss of wellbeing and productivity are the most important consequences in these patients. Appropriate diagnosis and treatment are necessary to improve patients' health and productivity, which will contribute to reducing societal costs (17).

\section{Acknowledgements}

Members of the Italian Hand Eczema Study Group: Dr Anna Belloni Fortina and Dr Ilaria Romano (University of Padua, Padua); Dr Giuseppe Pellegrini (University of Bari 'Aldo Moro', Bari); Professor Giampiero Girolomoni and Dr Donatella Schena (University of Verona, Verona); Dr Fabrizio Guarneri (University of Messina, Messina); Dr Mirko Frasca (Institute San Gallicano, IRCCS, IFO, Rome); Dr Angelo Massimiliano D'erme and Dr Nicola Milanesi (University of Florence, Florence); Dr Valerio Pedrelli (University of Milan, Milan); Dr Konstantina Christana (University of Genoa, Genoa); Professor Paolo Lisi, Dr Katharina Hansel, and Professor Luca Stingeni (University of Perugia, Perugia); Dr Patriza Pepe (University of Modena and Reggio Emilia, Modena); Dr Arianna Ruggiero (Istituto Dermopatico dell'Immacolata (IDI)-IRCCS, Rome); Professor Giovanni Borroni and Dr Michela Castello (Institute of Dermatology, Pavia); Professor Fabio Ayala, Dr Donata Martellotta, and Dr Cataldo Patruno (University of Naples Federico II, Naples).

\section{References}

1 Smith H A, Burdorf A, Coenraads P J. Prevalence of hand dermatitis in different occupations. Int J Epidemiol 1993: 22: 288-293.

2 Dickel H, Bruckner T, Berhard-Klimt C, Koch T, Scheidt R, Diepgen T L. Surveillance scheme for occupational skin disease in the Saarland, FRG: first report from BKH-S. Contact Dermatitis 2002: 46: 197-206.

3 Diepgen T L, Agner T, Aberer W, Berth-Jones J, Cambazard F, Elsner P, McFadden J, Coenraads P J. Management of chronic hand eczema. Contact Dermatitis 2007: 57: 203-210.

4 Apfelbacher C J, Akst W, Molin S et al. CARPE: a registry project of the German Dermatological Society (DDG) for the characterization and care of chronic hand eczema. J Dtsch Dermatol Ges 2011: 9: 682-688.

5 Ruzicka T, Lynde C W, Jemec G B E et al. Efficacy and safety of oral alitretinoin (9-cis retinoic acid) in patients with severe chronic hand eczema refractory to topical corticosteroids: results of a randomized, double-blind, placebo-controlled, multicentre trial. Br J Dermatol 2008: 158: 808-817.

6 Schmitt-Hoffmann A H, Roos B, Sauer J, Spickerma J. Pharmacokinetics, efficacy and safety of alitretinoin in moderate or severe chronic hand eczema. Clin Exp Dermatol 2011: 36 (Suppl. 2): 29-34.

7 Dirschka T, Reich K, Bissonnette R, Maares J, Brown T, Diepgen T L. An open-label study assessing the safety and efficacy of alitretinoin in patients with severe chronic hand eczema unresponsive to topical corticosteroids. Clin Exp Dermatol 2011: 36: $149-154$.

8 McCall B P, Horwitz I B, Feldman S R, Balkrishnan R. Incidence rates, costs, severity, and work-related factors of occupational dermatitis: a workers' compensation analysis of Oregon, 1990-1997. Arch Dermatol 2005: 141: 713-718.

9 Meding B, Wrangsjö K, Jarvholm B. Fifteen-year follow-up of hand eczema: persistence and consequences. $\mathrm{Br} J$ Dermatol 2005: 152: 975-980.

10 Augustin M, Kussner D, Purwins S, Hieke K, Posthumus J, Diepegen T L. Cost-of-illness of patients with chronic hand eczema in routine care: results from a multicenter study in Germany. $\mathrm{Br} J$ Dermatol 2011: 165: 845-851.

11 Basra M K A, Chowdhury M M U, Smith E V, Freemantle N, Piguet V. Quality of life in psoriasis and chronic hand eczema: the discrepancy in the definition of severity in NICE guidelines and its implications. $\mathrm{Br} \mathrm{J}$ Dermatol 2012: 166: 462-463.
12 Cvetkovski R S, Rothman K J, Olsen J, Mathiesen B, Iversen L, Johansen J D, Agner T. Relation between diagnoses on severity, sick leave and loss of job among patients with occupational hand eczema. Br J Dermatol 2005: 152: 93-98.

13 Rodgers M, Griffin S, Paulden M, Slack R, Duffy S, Ingram J R, Woolacott N, Sculpher M. Alitretinoin for severe chronic hand eczema: a nice single technology appraisal. Pharmacoeconomics 2010: 28: 351-362.

14 Agner T, Andersen K E, Brandao F M et al. Hand eczema severity and quality of life: a cross-sectional, multicentre study of hand eczema patients. Contact Dermatitis 2008: 59: $43-47$.

15 NICE. NICE technology appraisal guidance 177, 2012. Available at: http://guidance.nice.org.uk/TA177 (last accessed 20 January 2013).

16 Drummond M, Sculpher M J, Torrance G W, O'Brien B J, Stoddart G L. Methods for the Economic Evaluation of Health Care Programmes, 3rd edition: Oxford, Oxford University Press, 2005.

17 Cortesi P A, Scalone L, De Pità O et al. Prevalence and cost of severe chronic hand eczema refractory to topical potent corticosteroids. Value Health 2011: 14: A490.

18 Coenraads P J, Van Der Walle H, Thestrup-Pedersen K et al. Construction 
and validation of a photographic guide for assessing severity of chronic hand dermatitis. Br J Dermatol 2005: 152 : 296-301.

19 World Medical Association (WMA). WMA declaration of Helsinki. In: Adopted by the 18th WMA General Assembly, Held in Helsinki in June 1964. Available at: http://www.wma.net/en/30publications /10policies/b3/index.html (last accessed 31 October 2012).

20 Sehgal V N, Srivastava G, Ashok K, Aggarwal A K, Sharma A D. Hand dermatitis/eczema: current management strategy. J Dermatol 2010: 37: 593-610.

21 AIFA - Italian Medicine Agency. Available at: http://farmaco.agenziafarmacoit/in dex.php (last accessed 31 October 2012).

22 AGENAS. Tariffari regionali delle prestazioni di assistenza ospedaliera provided under the hospitalization and day-hospital. Available at: http://www .agenas.it/monitoraggio_costi_tariffe/ monitoraggio_costi_tariffe_osp_acuti_r iabilitazione.htm (last accessed 31 October 2012).

23 AGENAS. The regional 'Nomenclatore Tariffario Regionale' for outpatient costs. Available at: http://www.agenas.it/moni toraggio_costi_tariffe/monitoraggio_costi _tariffe_prestazioni.htm (last accessed 31 October 2012).

24 Van Roijen L, Essink-Bot M L, Koopmanschap M A, Bonsel G, Ritten F F.
Labor and health status in economic evaluation of health care. The Health and Labor Questionnaire. Int J Technol Assess Health Care 1996: 12: 405-415.

25 ISTAT - Italian National Institute of Statistics. Available at: http://dati.istat.it/Index.aspx (last accessed 31 October 2012).

26 Brooks R. Euroqol: the current state of play. Health Policy 1996: 37: 53-72.

27 Baranzoni N, Scalone L, Mantovani L G, de Portu S, Monzini M S, Giannetti A. Validation of the Italian version of the Dermatology Life Quality Index. G Ital Dermatol Venereol 2007: 142: 209-214.

28 Lewis V, Finlay A Y. 10 Years experience of the Dermatology Life Quality Index (DLQI). J Investig Dermatol Symp Proc 2004: 9: 169-180.

29 Stamuli E. Health outcomes in economic evaluation: who should value health? $\mathrm{Br}$ Med Bull 2011: 97: 197-210.

30 Bingeford K, Lindberg M, Isacson D. Quality of life of topical medications and socio-economic data in hand eczema: a Swedish nationwide survey. Acta Derm Venereol 2011: 91: 452-458.

31 Deudén E, Griffiths C E, Ortonne J P et al. Improvements in patient-reported outcomes in moderate-to-severe psoriasis patients receiving continuous or paused etanercept treatment over 54 weeks: the CRYSTEL study. J Eur Acad Dermatol Venereol 2009: 23: 1374-1382.
32 Moberg C, Alderling M, Meding B. Hand eczema and quality of life: a population-based study. Br J Dermatol 2009: 161: 397-403.

33 Kind P, Dolan P, Gudex C, Williams A. Variations in population health status: results from a United Kingdom national questionnaire survey. BMJ 1998: 316 : 736-741.

34 Dolan P. Modelling valuations for EuroQol health states. Med Care 1997: 35: 1095-1108.

35 Badia X, Roset M, Herdman M, Kind P. A comparison of United Kingdom and Spanish general population time trade-off values for EQ-5D health states. Med Decis Making 2001: 21: 7-16.

36 Hongbo Y, Thomas C L, Harrison M A, Salek M S, Finlay A Y. Translating the science of quality of life into practice: what do Dermatology Life Quality Index scores mean? J Invest Dermatol 2005: 125 : 659-664.

37 Cvetkovski R S, Zachariae R, Jensen H, Olsen J, Johansen J D, Agner T. Quality of life and depression in a population of occupational hand eczema patients. Contact Dermatitis 2006: 54: 106-111.

38 Lan C C, Feng W W, Lu Y W et al. Hand eczema among University Hospital nursing staff: identification of high-risk sector and impact on quality of life. Contact Dermatitis 2008: 59: 301-306. 